\title{
Considerations on the importance of the main chemical properties of the soil in agrochemical studies
}

\author{
Sebastian Muraru ${ }^{1,{ }^{*}}$, Vergil Muraru ${ }^{1}$, Paula Condruz $^{1}$, Cornelia Muraru Ionel ${ }^{1}$, and Raluca Sfiru ${ }^{1}$ \\ ${ }^{1}$ National Institute of Research - Development for Machines and Installations Designed for Agriculture and Food Industry - \\ INMA Bucharest,Computer Engineering Department, no 6, Blv. Ion Ionescu de la Brad, Romania
}

\begin{abstract}
Information on soil nutrition level or soil pollution level can lead to the establishment of some recommendations or a strategic decision-making program for the reference area development. The specific soil analysis is essential both from an economic point of view and from an environmental point of view. To achieve an adequate management of the nutrients into an agricultural field, it is necessary to conduct an agrochemical study at an interval of 3-5 years, in which, the relevant agrochemical indicators for the evaluation of the nutrient supply state must be analysed, to determine fertilizer doses and/or recommended amendments for the expected crops. The agrochemical study must contain the analysis bulletin that provides the following information: $\mathrm{pH}$ value, humus and total nitrogen content, phosphorus $(\mathrm{P})$ and potassium $(\mathrm{K})$ content, $\mathrm{C} / \mathrm{N}$ ratio (carbon / nitrogen), nitrogen index (NI), as well as the main microelements.
\end{abstract}

\section{Introduction}

Soil, the natural environment for plant growth and ecosystem survival, is a heterogeneous polydispersion system consisting of three states of aggregation of matter: solid, liquid and gaseous.

Most of the nutrients contained in the soil in larger quantities are: $\mathrm{Si}, \mathrm{Al}, \mathrm{Ca}, \mathrm{Mg}, \mathrm{K}, \mathrm{Fe}, \mathrm{Na}, \mathrm{P}$ and are fixed in the primary and secondary minerals from which the soil comes from. They cannot be absorbed directly by plants, but only after their passage into the liquid phase, as a result of the disaggregation and alteration processes.

The ions released by alteration can be retained by adsorption processes on the colloidal side of the soil, or they can recombine with other ions and precipitate. The intensity of alteration of primary and secondary minerals primarily depends on temperature, humidity and $\mathrm{pH}$. [1,2].

Agricultural lands cannot maintain their production capacity because impoverish in nutrients. Knowing the relationships between plant, soil and environment must reach a balance.

To do this, we must first determine the soil fertility. Soil properties of composition, dispersion, indoor activity as well as physical, chemical, biochemical processes, which determine the soil fertility.

An agrochemical study can provide the necessary data regarding the pedoclimatic situation from the agricultural field, and must contain the analysis bulletin that provides the following information: soil reaction by $\mathrm{pH}$ value, the content of organic matter (humus); total nitrogen; phosphorus $(\mathrm{P})$ and potassium $(\mathrm{K})$ content, as well as the main microelements, [3].

Depending on the soil reaction, other agrochemical fertility indices can also be determined: alkaline earth carbonates and soluble salt content and cation exchange capacity, as well as the calculation of synthetic indices such as: $\mathrm{C} / \mathrm{N}$ ratio (carbon / nitrogen) and nitrogen (IN).

An accurate knowledge of the soil characteristics gives us exact information about what amounts of fertilizer, we will have to use in the coming years, [4]. Thus, we will be able to save money because we will not waste money on chemicals that exist in the soil and which, if they are in excess, can damage crops.

pH- It is a characterization indicator of the soil reaction and expresses the property of the soil to dissociate in its own hydrogen ions $(\mathrm{H}+)$ solution or hydroxyl ions $(\mathrm{OH}-)$.

Soil acidity represents both hydrogen ions $(\mathrm{H}+)$ absorbed at the surface of colloidal particles and those in the free state in solution. It is characterized by two parameters: one of intensity and another of quantity, [5].

\footnotetext{
* Corresponding author: sebi_muraru@yahool.com
} 
The intensity parameter represents the activity of hydrogen ions absorbed at the particles surface, which can pass from the solid part of the soil in the form of ions, in water or in saline solutions with which the soil comes into contact. It is called current acidity and is practically materialized through the pH values.

In fact, when determining the $\mathrm{pH}$ of the soil in aqueous or alkaline solution, only the current acidity is determined. Theoretically, the $\mathrm{pH}$ values oscillate between 0 and 14. The average value of the $\mathrm{pH}$ scale (7), corresponds to a neutral reaction, and the values lower and higher than 7 show an acidic reaction, respectively, basic. Basically, for the soil, the $\mathrm{pH}$ scale is narrower, between the values of 4 and 11 .

The actual acidity of the soil depends on the environment in which it is determined. The $\mathrm{pH}$ indicator of acid soils is numerically lower when is measured in the suspension than if it were measured in the filtered solution, that was in equilibrium with the soil. It is necessary to standardize the conditions for measuring the $\mathrm{pH}$ in the laboratory. Among the methodological effects we mention the dilution effect, the $\mathrm{CO}_{2}$ effect in the air and the saline effect.

Decreasing the soil: water ratio (increasing of the soil suspension dilution) increases the $\mathrm{pH}$ value in the case of both acidic and alkaline soils. Hence the need to standardize the soil: water ratio (mass / volume): for arable soils, meadows and orchards and vineyards is 1: 2.5 , for greenhouse soils intended for vegetables is $1: 5$; in greenhouse soils intended for flower crops, composts, nutrient mixtures, peat with a content of organic matter determined by loss during calcination $\left(600^{\circ} \mathrm{C}\right)$, as well as soil horizons with a content of over $30 \%$ organic matter (humus) is used a ratio of $1: 10$.

For all soil types, the saline suspension $\mathrm{pH}\left(\mathrm{pH}_{\mathrm{KCl}}\right)$ is determined in a saline suspension of potassium chloride, $0.1 \mathrm{n} \mathrm{KCl}$, at a soil: solution ratio of 1: 2.5 (mass / volume).

The influence of $\mathrm{CO}_{2}$ from atmospheric air dissolved in the suspension on $\mathrm{pH}$ differs depending on the reaction of the soil. In the case of soils with $\mathrm{pH}>6.0 \mathrm{CO}_{2}$ the $\mathrm{pH}$ values decrease, and in soils with $\mathrm{pH}<6.0 \mathrm{CO}_{2}$ does not significantly influence the $\mathrm{pH}$ value (dissociation $\mathrm{H}_{2} \mathrm{CO}_{3}$ is insignificant).

In the field, the soil $\mathrm{pH}$ changes depending on the variation in water content and soluble salt content: in the hot and dry season increase the content of soluble salts-nitrates, sulfates, chlorides-accumulated in the soil , which leads to a lower $\mathrm{pH}$ value; in the rainy season the salts are dissolved and transported in the groundwater (leaching), the $\mathrm{pH}$ increasing up to its maximum value in the respective soils.

Fertilization in soil with soluble salts $\left(\mathrm{NH}_{4} \mathrm{NO}_{3}, \mathrm{~K}_{2} \mathrm{SO}_{4}\right)$ leads to an immediate significant decrease in soil $\mathrm{pH}$. This effect decreases rapidly through consumption by plants, through ion exchange reactions, by fixation in complexes and by leaching.

The $\mathrm{pH}$ value defines the soil reaction class and the representation colors on the agrochemical cartograms:

\begin{tabular}{|c|c|c|c|c|c|}
\hline $\begin{array}{c}\text { Strongly } \\
\text { acidic }\end{array}$ & $\begin{array}{c}\text { Moderately } \\
\text { acidic }\end{array}$ & $\begin{array}{c}\text { Weakly } \\
\text { acidic }\end{array}$ & Neutral & $\begin{array}{c}\text { Weakly } \\
\text { alkaline }\end{array}$ & $\begin{array}{c}\text { Moderately } \\
\text { and strongly } \\
\text { alkaline }\end{array}$ \\
\hline $\mathrm{pH} \leq 3,55$ & 5,8 & 6,8 & 7,2 & 8,4 & $>8,41$
\end{tabular}

The quantity parameter is given by the hydrogen ions adsorbed on the colloidal particles surface of clay minerals and humic substances, determined as the titratable acidity of the soil to a conventionally established end point and represents the potential acidity, [5].

Perfectly dry soil contains only potential acidity; as the hydrogen ions pass into solution it becomes current acidity. A dynamic balance is maintained between the potential acidity and current acidity, the decrease of the potential acidity decreases the current acidity. The potential acidity of the soil has 3 components: exchange acidity $(\mathrm{Ea})$; hydrolytic acidity $(\mathrm{Ha})$; neutralizing acidification.

\section{Materials and methods}

\subsection{The importance of determining the $\mathrm{pH}$ value}

The $\mathrm{pH}$ parameter of the soil is a very important element, it needs to be known and monitored because it intervenes in many physico-chemical and biological mechanisms in the soil. About the importance of the value of the $\mathrm{pH}$ index in the general chemistry of the soil we can say the following:

1) It sufficiently characterizes the soil, offering a global image of its trophicity. Because the activity of hydrogen ions also determines the activity of other ions in the soil solution, the $\mathrm{pH}$ value is important in assessing soil fertility, [4].

2) Appreciates the state of opportunity for the amendment of acid soils and the improvement of alkaline soils. Most crop plants do not tolerate a pH below 4.5 or $8.3 \mathrm{pH}$ units, [6]. Most plants grow best on neutral soils, meaning $\mathrm{pH}=6.8-7.2$ or slightly acidic- $\mathrm{pH}=6.3-6.8$. The $\mathrm{pH}$ of the soil is adjusted according to the plants that will be grown. 
To the acidic soils, the colloidal complex is saturated with hydrogen ions, leading to unfavorable physical properties (the structure is poorly formed or degraded, the porosity is low, small permeability for water and air). Therefore, the acid reaction imposes unfavorable physical, chemical and biological properties in the soils, which have a low productive capacity. Therefore, the $\mathrm{pH}$ value is an index of appreciation of the application of calcareous amendments to acid soils, along with the degree of saturation in basic cations and the presence of exchangeable aluminum.

In addition, the strongly alkaline reaction has an unfavorable influence on the properties and productive capacity of soils. Basically, plants start to suffer when the $\mathrm{pH}$ value rises above 8.5.

If the soils contain salts that hydrolyze alkaline ( $\mathrm{Na} 2 \mathrm{CO} 3$ has the strongest basic character), they release $\mathrm{OH}-$ ions in solution and give to the soil solution an alkaline reaction. By the hydrolysis of carbonates in the soil results bases and carbonic acid, an acid that decomposes into carbon dioxide (CO2) and water (H2O). The bases strongly dissociate in aqueous solution, releasing large amounts of $\mathrm{OH}-$.

The high concentration of soluble salts in the soil solution causes to acquire a high osmotic pressure, which exceeds that of sucking roots, in these conditions, the plants can no longer absorb water from the soil with the nutrients, manifesting strongly the physiological drought phenomenon

The strongly alkaline reaction determines the blockage of some microelements ( $\mathrm{Cu}, \mathrm{Zn}, \mathrm{Bo}$, Mo, etc.), and the presence of sodium in large quantities imprints to the soil completely unfavorable physical properties. In strongly alkaline soils, the physical, chemical and biological properties are more unfavorable than the acid soils, they being practically infertile. The improvement of the strongly alkaline reaction is much more complicated, being achieved by administering amendments based on gypsum or phosphogypsum at the same time with the application of washing operations and drainage works, [3].

3) Affects the mobility and accessibility of soil nutrients. The soil $\mathrm{pH}$ can determine whether a plant can access or not the nutrients it needs. The solubility of soil constituents, both in soils that contain ions needed in plant nutrition and as well as those that can release ions that can become toxic to plants beyond certain limits, depends on $\mathrm{pH},[5]$.

If the soil reaction is acidic, with $\mathrm{pH}<5$, the amount of exchangeable calcium $\left(\mathrm{Ca}^{2+}\right)$ and magnesium $\left(\mathrm{Mg}^{2+}\right)$ ions decreases and the solubility of zinc $\left(\mathrm{Zn}^{2+}\right)$, aluminum $\left(\mathrm{Al}^{3+}\right)$, manganese $\left(\mathrm{Mn}^{2+}\right)$, copper $\left(\mathrm{Cu}^{2+}\right)$ ions increases. It also decreases the solubility of elements such as phosphorus and molybdenum, which are immobilized in insoluble complexes of iron, aluminum in the soil.

The decrease in $\mathrm{pH}$ decreases the cation exchange capacity and an increase in the anion exchange capacity by adding positively charged particles, $\mathrm{H}+$ ions.

If the soil reaction is a basic $(\mathrm{pH}>7.8)$, in the presence of exchangeable calcium and magnesium ions, hardly soluble salts are formed, such as monocalcium phosphate $\left(\mathrm{CaHPO}_{4}\right)$ and tricalcium phosphate $\left[\mathrm{Ca}_{3}\right.$ $\left(\mathrm{PO}_{4}\right)_{2}$ ]. Also, the compounds of iron, zinc and manganese pass into hardly soluble forms, inaccessible for plants.

The basic elements for a balanced soil, which decisively influences the development of $\mathrm{N}, \mathrm{P}, \mathrm{K}$ plants (nitrogen, phosphorus, potassium), are assimilated by them depending on $\mathrm{pH}$ values as follows: nitrogen is assimilated at $\mathrm{pH} 6-8.5$, phosphorus at a $\mathrm{pH} 6.5-8$ and potassium at a $\mathrm{pH}>6$.

The optimal $\mathrm{pH}$ range in which nutrients become accessible to the plants is between 6.0 and 7.0, [7]. The mobility of nutrients under acidic condition changes. The activity of microorganisms decreases, the $\mathrm{N}$ content decreases, implicitly the humus content decreases. Phosphorus retrograde by increasing the content of Fe and $\mathrm{Al}, \mathrm{Al}$ and $\mathrm{Fe}$ ions have a toxic effect on plants if they exceed certain limits. The soluble forms of $\mathrm{K}$ decreases with increasing acidity due to the immobilization of $\mathrm{K}$ in the structure of clay minerals. In the graphical representation below shows the quantities of macroelements $(\mathrm{N}, \mathrm{P}, \mathrm{K})$ adsorbed by plants at different $\mathrm{pH}$ values of the soil solution (Fig. 1): 


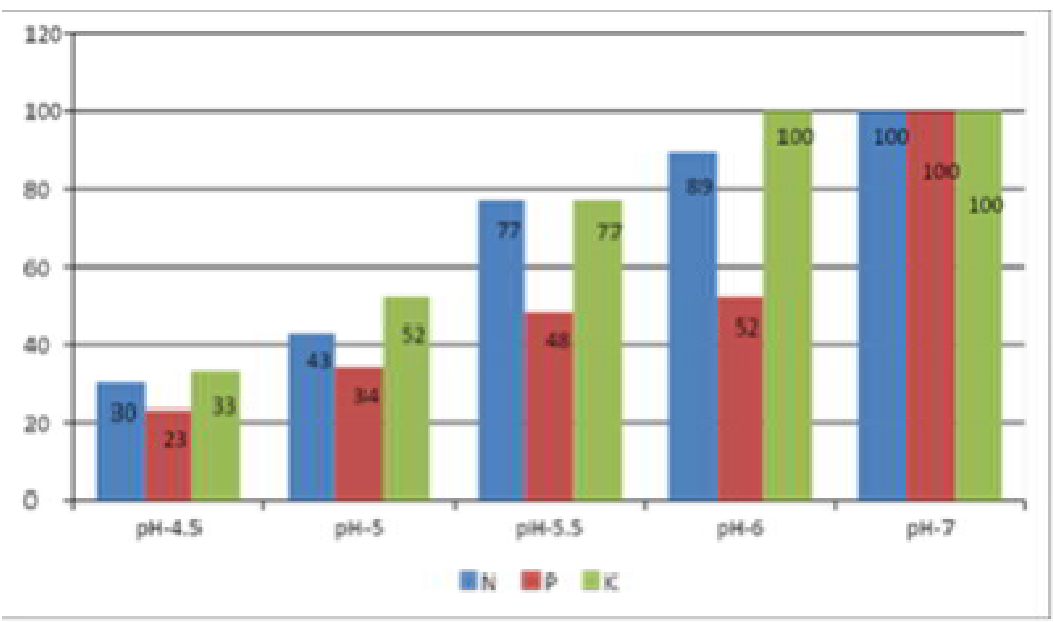

Fig. 1. Adsorption N, P, K by plants depending on the soil $\mathrm{pH}$

4) Influences the activity of microorganisms. Soil microbial diversity is responsible for the greatest transformation of nutrients in the soil, the regeneration of minerals that limit crop productivity. The reaction of the soil has a strong influence on the development of microorganisms in the soil. Thus, bacteria prefer a reaction from weakly acidic to alkaline ( $\mathrm{pH} 6-8)$, actinomycetes prefer a neutral or alkaline reaction $(\mathrm{pH} 7-7.5)$, and fungi grow under acidic reaction conditions ( $\mathrm{pH} 4-5)$.

At certain $\mathrm{pH}$ values, the activity of microorganisms shows an optimal activity [such as bacteria that transform atmospheric nitrogen (N2) into nitrogen from soil available in plants (NH4), [8]. In strongly acidic soils, bacteria living in symbiosis with leguminous plants, nitrogen-fixing bacteria, and nitrifying bacteria are almost completely absent. A low soil $\mathrm{pH}$ tends to favor the appearance of fungi, while a higher $\mathrm{pH}$ tends to favor bacteria, so that the importance of balancing the two becomes obvious: too low a $\mathrm{pH}$ can lead to the proliferation of fungal diseases. Fungi and bacteria are needed, but too much can lead to problems.

5) Influences the application of fertilizers. When fertilizing soils with mineral fertilizers, the soil reaction is taken into account, [3]. Usually, basic reaction fertilizers are applied on acidic soils, and acidic fertilizers are applied on alkaline ones. Particular attention should be paid to phosphorus fertilizers. On acid soils, due to their high solubilizing power, fertilizers based on tricalcium phosphate and even crude phosphorites are applied. The gradual release of phosphorus ions on these soils also has the advantage that it cannot be blocked in the form of iron or aluminum phosphates. On alkaline soils, it is recommended to apply slightly soluble superphosphate (monocalcic and dicalcic phosphate), [9].

6) The $\mathrm{pH}$ value is used to calculate synthetic agrochemical indices: Zinc deficiency index - ICZn; Mobile phosphate reaction index - IRPM; Molybdenum index - IMo; Reaction factor calculation of PAL values.

Humus. Soil humus is advanced organic matter in an advanced stage or various stages of transformation. It is a complex of organic compounds in a close correlation with the mineral part of the soil. The essential part of humus is humic substances (85\%-90\%) consisting mainly of humic acids, fulvic acids and their organomineral products.

Humic acids (black colour) are macromolecular compounds with a cyclic structure that contains carbon (50\%-65\%), hydrogen, oxygen, nitrogen (2\%-6\%). They are insoluble in water and acids, but slightly soluble in alkaline solutions. The presence in the molecular structure of the carboxylic and phenolic functional groups leads to exchange reactions between humic acids and the mineral part of the soil. Humic acids fixed to the mineral part of the soil can no longer pass into the solution when treating the soil with alkaline solutions. They have a high adsorption capacity and form a series of water-insoluble organo-mineral compounds, favoring the accumulation of nutrients in the upper part of the soil profile. Freshly formed humic acids, saturated with bases, especially with calcium, coagulate irreversibly, thus contributing to the formation of hydrostable structural aggregates

Humic acids are formed mainly from organic waste derived from grassy vegetation. When interacting with the mineral part of the soil, humic acid form compounds, called humites, which improve the structure and properties of the soil.

Fulvic acids of pale yellow colour (in low concentration in solution) up to an orange colour, are soluble in water, acids and alkaline solutions. They contain carbon (40\%-45\%), hydrogen, oxygen and nitrogen (3\%-4\%). It exerts strong alteration action due to the strong acid reaction (they have $\mathrm{pH}=2.6-2.8$ ), they allow the mobilization and deep displacement of different soil components. When interacting with the mineral part of the 
soil, fulvic acids form compounds, called fulvates, which also favor the alteration of the mineral part of the soil and the movement of nutritive elements.

\subsection{The importance of knowing the total humus content of the soil}

The humus content indicates the degree of soil fertility.

The soil with 3\%-4\% humus can provide during a vegetation period of $10-30 \mathrm{~kg}$ of N/ha in dry years and $80-100 \mathrm{~kg}$ of $\mathrm{N} / \mathrm{ha}$ in years with abundant rainfall. The soils have certain $\mathrm{C} / \mathrm{N}$ ratios, which, to a certain extent, reflect the nature of humus and as a result serves to it's characterization in relation to soil types. Along with other data, it gives indications of the richness of the soil in nitrogen, the main element of plant nutrition. Thus, the low $\mathrm{C} / \mathrm{N}$ ratio for chernozems (10-12) shows their nitrogen richness compared to podzolic soils, where the ratio is higher (13-14).

The $\mathrm{C} / \mathrm{N}$ ratio indicates the intensity of the decomposition of organic matter in the soil by microorganisms. $\mathrm{C} / \mathrm{N}=$ (Humus\% $\mathrm{x}$ 0.6767) / Nt.

$\mathrm{C} / \mathrm{N}<15$-very intense decomposition (humus). For soils in Romania, Cernescu (1941) established the following classifications: chernozems where $\mathrm{C} / \mathrm{N}$ is $12.5-13.5$; leachate chernozems where $\mathrm{C} / \mathrm{N}$ is $14-15$, brown forest soils where $\mathrm{C} / \mathrm{N}$ is $12.5-14$; secondary podzols where $\mathrm{C} / \mathrm{N}$ is $15.5-16$

$\mathrm{C} / \mathrm{N}=15-30$-average decomposition

$\mathrm{C} / \mathrm{N}>30$-reduced decomposition.

H\% = organic C $\mathbf{C} 1.7241$ where, 1.7241 - represents the amount of humus, in g, corresponding to $1 \mathrm{~g}$ of organic carbon (corresponding to the average percentage of carbon content in humus is $58 \%$ );

Due to their cation exchange capacity, humic substances can retain a series of cations $(\mathrm{Ca} 2+, \mathrm{Mg} 2+, \mathrm{Na}$ ,$+ \mathrm{K}+$ ), which, also through cation exchange, can be released and made available to plants. Together with clay, which also has this property, humus forms the adsorbent complex of the soil.

In the presence of clay, humic acids saturated with calcium cations cause the formation of the grainy structure of the soil. The presence of aggregates with high water stability creates in the soil an aerohydric regime favorable to the normal development of plants. Soil fertility depends not only on the humus content in the soil, but also on the degree of saturation of the adsorbent complex with $\mathrm{Ca} 2+$, which imprints the soil with the best physical and chemical properties. Due to its ability to stably cement mineral particles into structural aggregates, humus improves the physical properties of clay soils, reducing their cohesion and the same time increasing their permeability to air and water. Humus increases the cohesion of sandy soils, reduces their permeability to water and increases their retention capacity. Also, humus influences the thermal regime of the soil by the fact that imprinting dark colour contributes to the increase in caloric capacity. In the humus of the soil is concentrated a large amount of energy from solar energy. The energy, with the nutrients in the humus, releases the necessary amounts of nitrogen, phosphorus, potassium and carbon dioxide of plants.

In terms of plant nutrition, humus is the main source of nitrogen and phosphorus $(30 \%-50 \%$ phosphorus in the soil from humus and partially decomposed or undecomposed organic matter) from the soil as well as other nutrients. Humic substances in the soil also exert a direct influence on plants, stimulating their growth and development

Total nitrogen Nt. Over $90 \%$ of the nitrogen in the soil is organic in nature. It does not come like other nutrients from the rock on which it was formed, resulting from the biological activity that occurs in the organic matter in the soil and in which it is about 5\%. In the soil, the amount of total nitrogen varies on average in depth from 0 to $20 \mathrm{~cm}$, depending on the humus content, from $0.03 \%$ in soils poor in organic matter, to about $0.5 \%$ in chernozems $(2,5-10 \mathrm{t} / \mathrm{ha})$, and in the deeper horizons, it decreases, so that at a depth of 2-3 $\mathrm{m}$ it is almost missing. It was determined that at a depth of $1 \mathrm{~m}$ - in relation to the type of soil - the amount of nitrogen is 9 $30 \mathrm{t} / \mathrm{ha}$. The soil provides a good part of the nitrogen necessary for plant growth. It is present in the soil in the form of organic and mineral compounds, which, together, give the total available nitrogen. Nitrogen is taken from the soil mostly in the form of NH4 + or NO3- ions and to a lesser extent in the form of NO2- (because it oxidizes rapidly to nitrates), forms that come from the organic matter in the soil.

\subsection{The importance of knowing the total nitrogen content of the soil}

The regulation of the $\mathrm{N}$ regime in the soil, in relation to the requirements of the plants is one of the agrochemical measures. The values of the total $\mathrm{N}$ content are used to calculate the $\mathrm{C} / \mathrm{N}$ ratio, for assessing the state of nitrogen supply of soils, for characterizing organic matter.

$\mathrm{C} / \mathrm{N}=$ Humus, $\%$ x $0.6767 / \mathrm{Nt}, \%$

The appreciation of the level of total $\mathrm{N} \%$ : very small $<0.100$; small $0.100-0.140$; medium $0.141-0.270$; high $0.271-0.600$ and very high $>0.600$, [8].

Indirectly, the assessment of the nitrogen supply level of the soil can be done with the help of the nitrogen index (IN). It is a synthetic index that shows the ability of the soil to make available to the crop the amount of $\mathrm{N}$ 
from the humus mineralization. To determine the IN, the following must be determined: the sum of the exchangeable bases (SB) by the Kappen method, the hydrolytic acidity (Ah), by means of the KappenDaikuhara method and humus by the oxidimetric method, in the Walkley - Black variant.

IN = (Humus, \% x VAh) / 100 where VAh represents the degree of saturation in bases, [4]. The IN value represents the appreciation of the state of soil supply with nitrogen as follows: $\leq 2.0$ - poor; $2.1-4.0$ - medium; 4.1-6.0 - good; $\geq 6$-very good.

Phosphorus (P). The total phosphorus in the soil is given by the phosphorus of organic nature, $30 \%-50 \%$ (from humus and from the partially decomposed or undecomposed organic matter) and by the inorganic phosphorus, $50-70 \%$ (simple phosphates of calcium, magnesium, iron, aluminum, of complex phosphates and free ions in the soil solution or absorbed in the colloidal micelle). In acid soils, iron and aluminum phosphates predominate, in neutral or alkaline soils, calcium phosphates. The decomposition of organic matter results in orthophosphate anions soluble in the soil solution. The C: N: P ratio of soil organic matter is approx. 100: 10: 1. If the C: P ratio is less than or equal to 200: 1, phosphate ion mineralization occurs, if it is greater than or equal to 300: 1 phosphorus immobilization occurs, [9].

Knowing the total phosphorus content in the soil $(\% \mathrm{P})$, we can assess the fertility status of the soil as follows: $<0.044$ low fertility; $0.044-0.065$ average fertility; $>0.065$ high fertility. Of the total phosphorus content in the soil, only $0.5-1 \%$ is accessible to plants, its mobility in the soil being low.

Phosphorus is absorbed from the soil by plants either as H2PO4 monophosphate or as HPO42 diphosphate. The relative abundance of the two anions in the soil solution depends on the soil $\mathrm{pH}$ : if the soil $\mathrm{pH}$ increases, the proportion in the H2PO4 form - decreases and the HPO42 form - increases. At $\mathrm{pH}=7$, the concentration of the two anions is practically equal.

\subsection{The importance of knowing the content of soil PAL}

Based on the analytical data on the reaction and soil content in soluble phosphates extracted in ammonium acetate-lactate reagents or calcium, we can assess the state of supply with plant accessible phosphates (PAL).

In order for the PAL values to be interpreted using the same limit values for the different insurance classes, the analytical values obtained are corrected with a factor (FC), a correction factor that depends on the soil $\mathrm{pH}$.

Potassium (K). Potassium is the second most abundant nutrient after N, it is 4-6 times more abundant than macronutrients such as $\mathrm{P}, \mathrm{Ca}, \mathrm{Mg}$, and $\mathrm{S}$, and the most important cation for living organisms. Most of the potassium in the soil $(90 \%-98 \%)$ is in the crystal lattice of minerals (mica, feldspar, illite, chlorite, vermiculite, smectite and is inaccessible to plants except after alteration processes). Fixed potassium - retained between the sheets of the clay mineral network and can be assimilated by plants under certain conditions. Exchangeable potassium - is found in the form of ions retained in the colloidal complex of the soil and represents less than $1 \%$ of the total K. It is the main source of accessible potassium for plants, [10]. Soluble potassium - is found in the form of ions in the soil solution and represents only $1 \%$ of exchangeable potassium. Therefore, usually by exchangeable potassium in the soil, the sum between exchangeable potassium and soluble potassium is understood. There is a balance between all these forms of potassium in the soil.

Total potassium in the soil has no significance for its accessibility to plants but only rarely for the study of accumulation in soils in case of excessive application of potassium fertilizers.

Soluble and exchangeable potassium $(\mathrm{K}+)$ is the immediate source of plant nutrition with this element. As it is consumed by plants in the soil solution, the balance is restored by switching to solution (by cation exchange reactions) of exchangeable $\mathrm{K}$. To assess the soil potassium reserve, the value of the total potassium content in the soil is determined. The determined value of the mobile potassium content, extractable in ammonium acetatelactate solution (KAL), directly significant value for plant nutrition, establishes the soil content classes: $\leq 40$ $\mathrm{mgK} / \mathrm{Kg}$ soil - extremely small; 41-65 $\mathrm{mgK} / \mathrm{Kg}$ soil - very small; 66-130 $\mathrm{mgK} / \mathrm{Kg}$ soil - small; 131-200 $\mathrm{mgK} / \mathrm{Kg}$ soil-medium; 201-300 mgK/ Kg soil- high; $\geq 300 \mathrm{mgK} / \mathrm{Kg}$ soil - very high.

The main chemical properties that characterize soil well enough are: soil reaction $(\mathrm{pH})$, amount of humus $(\mathrm{H} \%)$, total nitrogen in the soil $(\mathrm{Nt})$, phosphorus $(\mathrm{P})$, potassium $(\mathrm{K})$.

\section{Results and discussion}

Laboratory analyses were performed on 12 average soil samples collected from lot 1 and on 13 average soil samples from lot 2 , presented in table 1 . The lots are at a distance of $10 \mathrm{~km}$ from each other. The supply status with $\mathrm{N}, \mathrm{P}$, and $\mathrm{K}$ of the respective lots was taken into account. 
Table 1

\begin{tabular}{|c|c|c|c|c|c|c|c|c|c|c|c|c|}
\hline \multirow[t]{3}{*}{ no } & \multirow[t]{3}{*}{ lot } & \multirow{3}{*}{$\begin{array}{c}\text { sample } \\
\text { no. }\end{array}$} & \multirow{3}{*}{$\begin{array}{c}\text { harvest } \\
\text { depth } \\
\text { cm }\end{array}$} & \multicolumn{9}{|c|}{ Analyses performed } \\
\hline & & & & $\mathrm{pH}$ & $\mathbf{H}$ & $\mathrm{Nt}$ & VAh & IN & PAL & KAL & $\overline{\mathbf{P t}}$ & Kt \\
\hline & & & & $\begin{array}{c}\text { Unit } \\
\text { pH }\end{array}$ & $\%$ & $\%$ & $\%$ & $\begin{array}{l}\text { IN=(H,\% } \\
\text { xVAh)/100 }\end{array}$ & $\mathrm{mg} / \mathrm{Kg}$ & $\mathrm{mg} / \mathrm{Kg}$ & $\%$ & $\%$ \\
\hline 1 & 1 & 01 & $0-25$ & $\overline{6,44}$ & 2,96 & 0.144 & 89,5 & 2,65 & 75 & $\overline{193}$ & 0,072 & 1,71 \\
\hline 2 & & 02 & $0-25$ & 6,25 & 3,20 & 0.151 & 87,7 & 2,80 & 45 & 205 & 0,058 & 1,08 \\
\hline 3 & & 03 & $0-25$ & 6,26 & 3,14 & 0.149 & 87,5 & 2,75 & 28 & 209 & 0,063 & 1,23 \\
\hline 4 & & 04 & $0-25$ & 6,24 & 3,61 & 0.174 & 87,7 & $\overline{3,16}$ & $\overline{43}$ & $\overline{201}$ & 0,065 & 1,28 \\
\hline 5 & & 05 & $0-25$ & 5,93 & 3,67 & 0.178 & 85,7 & 3,15 & 26 & 211 & 0,054 & 1,27 \\
\hline 6 & & 06 & $0-25$ & 5,97 & 3,55 & 0.176 & 87,5 & 3,11 & 63 & 217 & 0,071 & 1,31 \\
\hline 7 & & 07 & $0-25$ & 6,37 & 3,55 & 0.180 & 89,1 & 3,16 & 45 & 213 & 0,066 & 0,93 \\
\hline 8 & & 08 & $0-25$ & 6,27 & 3,43 & 0.172 & 86,9 & 2,98 & 27 & 184 & 0,070 & 0,90 \\
\hline 9 & & 09 & $0-25$ & 6,25 & 3,73 & 0.174 & 86,8 & 3,24 & 26 & 203 & 0,067 & 0,95 \\
\hline 10 & & 010 & $0-25$ & 6,17 & 3,37 & 0.151 & 88,4 & 2,98 & 37 & 203 & 0,070 & 1,00 \\
\hline 11 & & 011 & $0-25$ & 6,26 & 3,20 & 0.163 & 89,0 & 2,85 & 41 & 201 & 0,062 & 0,96 \\
\hline 12 & & 012 & $0-25$ & $\overline{6,76}$ & 3,26 & 0,169 & 92,7 & 3,02 & 39 & $\overline{203}$ & 0,064 & 0,74 \\
\hline & & & & & & & & & & & & \\
\hline 13 & 2 & 52 & $0-25$ & 8,02 & 3,55 & 0,207 & & & 21 & 182 & 0,080 & 0,97 \\
\hline 14 & & 53 & $0-25$ & 8,21 & 2,78 & 0,152 & & & $\overline{172}$ & 254 & 0,142 & 1,00 \\
\hline 15 & & 54 & $0-25$ & 8,27 & 2,49 & 0,136 & & & 115 & 303 & 0,118 & 0,84 \\
\hline 16 & & 55 & $0-25$ & 8,09 & 3,14 & 0,168 & & & 64 & 166 & 0,091 & 0,94 \\
\hline 17 & & 56 & $0-25$ & 8,21 & 2,55 & 0,153 & & & 171 & 297 & 0,131 & 0,67 \\
\hline 18 & & 57 & $0-25$ & 8,07 & 3,26 & 0,197 & & & 84 & 189 & 0,093 & 0,72 \\
\hline 19 & & 58 & $0-25$ & 8,06 & 3,91 & 0,262 & & & 58 & 231 & 0,086 & 0,73 \\
\hline 20 & & 59 & $0-25$ & 8,08 & 2,84 & 0,170 & & & $\overline{116}$ & 244 & 0,107 & 0,88 \\
\hline 21 & & 60 & $0-25$ & 7,90 & 3,73 & 0,205 & & & 78 & 189 & 0,091 & 1,01 \\
\hline 22 & & 61 & $0-25$ & 8,11 & 3,67 & 0,219 & & & 37 & 186 & 0,072 & 0,73 \\
\hline 23 & & 62 & $0-25$ & 8,06 & 3,67 & 0,234 & & & 47 & 272 & 0,077 & 0,52 \\
\hline 24 & & 63 & $0-25$ & 8,16 & 3,67 & 0,162 & & & 39 & 221 & 0,076 & 0,81 \\
\hline 25 & & 64 & $0-25$ & 8,11 & 3,67 & 0,259 & & & 53 & 290 & 0,085 & 0,82 \\
\hline
\end{tabular}

\subsection{Interpretation of the $\mathrm{pH}$ analysis performed}

From the analysis of the $\mathrm{pH}$ of the soil samples from the 2 lots, it is found that:

The $\mathrm{pH}$ values in the samples of lot 1 fall into the reaction class of weakly acidic soil, so it is in the $\mathrm{pH}$ range between 5.8 and 6.8. At $\mathrm{pH} 5.6-6.2$ the need for amendment is medium; at $\mathrm{pH}>6.3$, it is not necessary to correct the acid reaction. For this lot, we recommend the cultivation of sunflower, wheat, corn, soybeans, barley, barley, hemp, peas, spinach, celery, potatoes, zucchini, tomatoes, cucumbers, watermelon, basil, rosemary, thyme, sage, parsley, iris, marigold, watercress, plum, and currant. The $\mathrm{pH}$ values in Lot 2 samples fall into the reaction class of weakly alkaline soil, so it is in the $\mathrm{pH}$ range between 7.2 and 8.4. For this lot, we recommend the cultivation of sugar beet, fodder beet, lucerne, rapeseed, cauliflower, cabbage, salad, beans, mint, quince, sour cherry.

\subsection{Interpretation of humus analyses performed}

From the analysis of the soil samples collected from the two lots, we observed that we have a humus content in the range of 3-4\% (except for 4 samples), which corresponds to a soil with medium fertility. Calculating and analyzing the $\mathrm{C} / \mathrm{N}$ ratios $\mathrm{C} / \mathrm{N}=$ (Humus\% $\% 0.6767$ ) / Nt) it is found that they are less than 15 , so the process of decomposition of organic matter in the soil by microorganisms is very intense which shows us that along with humification occurs mineralization humus, thus returning to the soil variable amounts of nutrients. With the help of humus content and the degree of saturation in the bases, we can calculate the nitrogen index, a synthetic index that shows the ability of the soil to make available to the crop during the vegetation period, certain amounts of nitrogen by humus mineralization. $\mathrm{IN}=($ Humus, $\% \mathrm{xVAh}) / 100$ 


\subsection{Interpretation of total $\mathrm{N}$ analyses performed}

The content of the samples collected from lot 1 and lot 2 indicates a total nitrogen level in the middle soil (it is in the range $0.140 \%-0.270 \%$ ). Both batches have a $\mathrm{pH}$ in which nitrogen is assimilated very well ( $\mathrm{pH} 6$ 8.5). Calculating the nitrogen index for the soil samples from lot 1 , we can appreciate that the soil has an ability to make available to the crop during the vegetation period, certain amounts of nitrogen that fit it into the soil with medium insurance. Depending on the type of crop, the expected production, the degree of soil supply, recommendations can be made for fertilization with nitrogen fertilizers.

\subsection{Interpretation of phosphorus analyses performed}

Lot 1 of soil has a good supply of phosphorus accessible to plants for field crops, natural and cultivated meadows, extensive plantations of trees and vines. For vegetables grown in the field, intensive plantations of fruit trees, vines, hops, nursery vineyards and orchards, insurance with phosphorus accessible to plants is poor. Lot 2 of soil has an excellent supply of accessible phosphorus for vegetables grown in the field, intensive plantations of fruit trees, vines, hops, vine and fruit nurseries, but the supply is excessive for other plants (even toxic). Both batches fall within the $\mathrm{pH}$ range in which phosphorus is well assimilated ( $\mathrm{pH} 6.5$ and 8 ).

\subsection{Interpretation of potassium analyses performed}

Both batches have good availability for potassium, $\mathrm{pH}>6$ favoring the assimilation of potassium in the proportion of $100 \%$.

\section{Conclusions}

Along with the analysis of $\mathrm{pH}$, humus, degree of saturation in the bases, the analysis of macronutrients $\mathrm{N}$, $\mathrm{P}, \mathrm{K}$ is very important in establishing the degree of fertilization of a soil in making fertilizer recommendations with these nutrients and not only. Depending on the result of the analysis, the type and facility of fertilizer application differ from case to case. To better exemplify the link between soil qualities and fertilization, the main problems should be shown, both on alkaline and acid soils. Plants prefer slightly acidic solutions, which are easily metabolized by plants. Where the $\mathrm{pH}$ is alkaline, it is good to apply foliar fertilizers. By administering phosphorus-based fertilizers in alkaline soils, we make the situation even more difficult and the action of nitrogen is blocked. Alkaline $\mathrm{pH}$ also confuses the situation with seed treatment. Due to the alkalinity, the effect of insecticides is neutralized. In addition, iron, phosphorus and manganese are blocked in alkaline soils. Fertilization recommendations must consider the cultivated plant, the production, we want to obtain, the degree of soil supply of nutrients and last but not least, must respect the principle of soil fertility conservation. In the elaboration of the fertilization plans, the specific nutritional consumption of the crop per ton of product, the expected quantity of product obtained per hectare, the reserve of nutrients in the soil is taken into account. The methods of fertilization, the technologies used, involve an optimal recovery of nutrients in the soil, a fertilization with minimal risks of soil pollution and groundwater.

This work was supported by a grant of the Ministry of Research, Innovation and Digitization (MRID), CCCDI UEFISCDI, project number PN-III-P1-1.2-PCCDI-2017-0560 "Eco-nanotechnologies and intelligent equipment for soil properties mapping and evaluating the dynamics of the plant in order to improve agricultural production and environmental protection, within PNCDI III

\section{References}

1. P. Cardei, S.L. Muraru, R. Sfiru, V. Muraru. General structure of tillage draft force. consequences in experimental and applicative researches, INMATEH - Agricultural Engineering,Vol. 59, No. 3, 256260,(2019)

2. Z. Borlan, C. Rauta, Methodology for agrochemical analysis of soils to establish the need for amendments and fertilizers, vol 2, Methods, guidance reports Series, ICPA no. 3, (1981)

3. D. Davidescu, L. Calancea, V. Davidescu, Gh. Lixandru, Agrochemistry, (Didactic and Pedagogical Publishing House Bucharest, 1981)

4. D. Davidescu, Z. Borlan, V. Davidescu, C. Hera, Phosphorus in agriculture, (Publishing House of the Academy of the Socialist Republic of Romania, Bucharest, 1974) 
5. D. Davidescu, V. Davidescu, L. Calancea, M. Handra, Nitrogen in agriculture, (Publishing House of the Academy of the Socialist Republic of Romania, Bucharest, 1976)

6. D. Davidescu, V. Davidescu, Potassium in agriculture (Publishing House of the Academy of the Socialist Republic of Romania, Bucharest, 1979)

7. R. Lacatusu, Agrochemistry, (Helicon Publishing House, Timisoara, Romania, 2000)

8. R. Lacatusu, Mineralogy and soil chemistry, (Publishing House of „Alexandru Ioan Cuza” University of Iași, Romania, 2000)

9. R. Lacatusu, M. Lungu, N. Rizea, Global soil chemistry, Terra Nostra Publishing House, 2017)

10. R. Madjaru, V. Davidescu, Agrochemistry, Distance learning course, Faculty of Horticulture, Bucharest, 2009. 